\title{
Towards multi-sensor microwave remote sensing of frost flowers on sea ice
}

\author{
Lars KALESCHKE, Georg HEYGSTER \\ Institute of Environmental Physics, P.O. Box 330440, D-28334 Bremen, Germany \\ E-mail: lars@seaice.de
}

\begin{abstract}
It has been hypothesized that frost flowers could be important for tropospheric chemistry and, as a source of sea-salt aerosol, for the interpretation of ice-core data. Furthermore, frost flowers can cause severe errors in sea-ice products derived from remote-sensing data. Up to now there have been few datasets available relating frost-flower distribution and variability in the sea-ice-covered regions. We present a method for frost-flower detection using a combination of active and passive microwave sensors. The vertical polarized C-band radar backscatter of a young sea-ice region covered with frost flowers can be higher than the signal from multi-year ice or from the wind-roughened ocean. Therefore, the classification result of synthetic aperture radar (SAR) sea-ice images can be defective due to the influence of frost flowers. The ambiguity of the open-water and frost-flower backscatter signal was successfully resolved using additional information from the $85 \mathrm{GHz}$ Special Sensor Microwave/ Imager (SSM/I) channels. Results of the method were compared to aircraft measurements and observations in the marginal ice zone near Svalbard.
\end{abstract}

\section{INTRODUCTION}

Frost flowers, also referred to as salt flowers, are a very common sea-ice feature in the Arctic and the Antarctic during the cold seasons (Perovich and Richter-Menge, 1994). Frost flowers grow on newly formed sea ice from a layer of supersaturated vapour (Martin and others, 1996). The thermo-molecular pressure gradient transports brine from the ice interior towards the surface where it is then drawn onto the crystals due to surface tension causing high salinities of up to 150 psu (Drinkwater and Crocker, 1988). Frost flowers are extremely effective collectors of blowing snow and quickly become snow-covered. Thus, layers of saline snow or slush are formed (Ulander and others, 1995). The frost-flower layer is significantly modified within several days (Perovich and Richter-Menge, 1994).

There has been considerable interest in tropospheric bromine chemistry due to its role in ozone depletion (McElroy and others, 1999). Severe ozone depletion events which take place in the polar regions during springtime are associated with enhanced $\mathrm{BrO}$ occurrence (Wagner and Platt, 1998). Furthermore, $\mathrm{BrO}$ was recently proposed to be a key oxidant converting long-lived gaseous elemental mercury to total particulate-phase mercury and/or reactive gaseous mercury. This oxidative transformation process is believed to greatly enhance the deposition flux of this toxic heavy metal to the fragile polar biosphere (Ebinghaus and others, 2002).

Satellite observations show that $\mathrm{BrO}$-enriched air masses are always situated close to sea ice (Richter and others, 1997). The high amount of bromine in the boundary layer can be explained by auto-catalytic release from sea salt. A heterogeneous mechanism leads to an exponential increase of reactive gas-phase bromine, the so-called bromine explosion, since every $\mathrm{Br}$ atom entering the liquid phase has the potential to release two $\mathrm{Br}$ atoms to the gas phase (Hönninger and Platt, 2002). Frost flowers provide a high relative surface area similar to fresh snow, i.e. $0.2-2 \mathrm{~m}^{2} \mathrm{~g}^{-1}$ (Perovich and Richter-Menge, 1994). The surface area relative to the area covered gives a factor of about 50-1000. Recently, Rankin and others (2002) found bromide concentrations in frost flowers that were around three times higher than in sea water. The combination of high bromide concentrations present in the liquid phase and the large surface area presented for exchange highlights the frost flowers as a potential source for tropospheric bromine.

Rankin and others (2002) suggested that frost flowers are the source for the majority of sea salt transported inland as aerosol during winter. So far, sodium concentrations in ice cores have been used to deduce changes in the amount of sea-salt aerosol. The sea salt has been assumed to come from open water only. The larger sea-ice extent should cause a decreased entrainment of sea salt during glacial periods due to the larger distance from the open water. In fact the high levels of sea salt from glacial periods have been attributed to a more efficient zonal and meridional atmospheric transport (Petit and others, 1999). This interpretation of high sodium concentrations being due to increased cyclonic activity may be incorrect: it may rather be an indicator of increased seaice and frost-flower production.

Frost flowers change the electromagnetic properties of the newly formed sea-ice surface in the microwave as well as in the optical region of the electromagnetic spectrum. As the flowers protude a few centimetres above the surface into the boundary layer, the infrared temperature measured from the satellite is about $4-6 \mathrm{~K}$ colder than that of the same ice cleared of flowers (Martin and others, 1996). At C-band $(\lambda \approx 5.6 \mathrm{~cm})$ the brine-enriched slush layer under the frost flowers dominates the backscatter. The surface of the frostflower crystals (surface roughness $\sigma \approx 0.5 \mathrm{~cm}$ ) appears rough at Ku-band $(\lambda \approx 2.2 \mathrm{~cm})$, yielding predominant surface scattering (Drinkwater and Crocker, 1988). Ulander and others (1995) observed an increase of 5-10 dB for European Remote-sensing Satellite (ERS) backscatter, with the largest increase occurring for snow-infiltrated frost flowers. Using combined ERS synthetic aperture radar (SAR) and Landsat data, two different nilas backscatter classes were found at -17 and $-10 \mathrm{~dB}$, with the latter class believed to be affected 


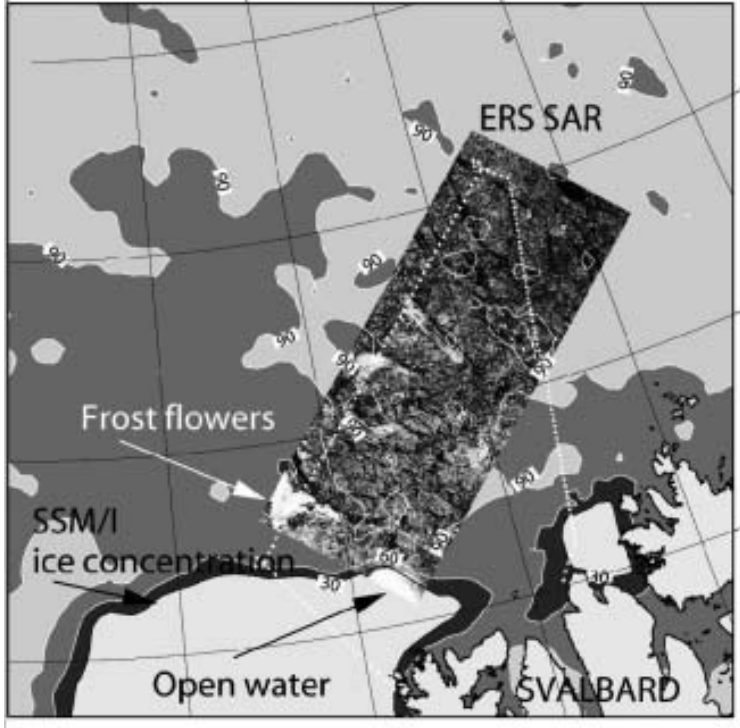

Fig. 1. ASI ice-concentration isolines, ERS SAR images and flight pattern of the Polar 4 on 12 March 1998.

by frost flowers (Steffen and Heinrichs, 1994). Zabel and others (1996) suggested using the frost-flowers signal to classify ice roughly $5-20 \mathrm{~cm}$ thick.

It is difficult to analyze the SAR images recorded with ERS-2 since the ambiguities in the mean normalized radar cross-section $\sigma^{\circ}$ in general do not allow unique assignments to surface types. The ambiguity of the open-water and frostflower backscatter signal can be resolved by using additional sea-ice concentration information derived from the $85 \mathrm{GHz}$ Special Sensor Microwave/Imager (SSM/I) channels. The 19 and $37 \mathrm{GHz}$ channels of the SSM/I have been commonly used for sea-ice concentration retrievals (Comiso and others, 1997). The ARTIST Sea Ice (ASI) algorithm is a hybrid algorithm combining the model of Svendsen and others (1987) for the $85 \mathrm{GHz}$ channels with a weather filter for the other SSM/I channels (Kaleschke and others, 2001). The $85 \mathrm{GHz}$ channels provide higher spatial resolution and sampling rate $(12.5 \mathrm{~km}$ vs $25 \mathrm{~km})$ than the 19 and $37 \mathrm{GHz}$ channels. There are about 64 measurements from the $85 \mathrm{GHz}$ channels $\left(15 \times 13 \mathrm{~km}^{2}\right.$ resolution), and only 4 independent measurements from the $19 \mathrm{GHz}$ channels $\left(69 \times 43 \mathrm{~km}^{2}\right.$ resolution), for each $100 \times 100 \mathrm{~km}^{2}$ SAR frame. In this paper, we present a feature-level data-fusion sea-ice classification method for ERS SAR and SSM/I. The method was evaluated using satellite underflights during the Arctic Radiation and Turbulence Interaction STudy (ARTIST), which was conducted in the environment of the Svalbard archipelago in March and April 1998 (Augstein, 2000).

\section{METHOD}

First, the incidence-angle dependence

$$
B=\frac{\partial \sigma^{\mathrm{o}}(\theta)}{\partial \theta}
$$

of the radar backscatter is estimated. The backscatter (in dB) can be described approximately by the linear relation (Ezraty and Cavaine, 1999),

$$
\sigma^{\mathrm{o}}(\theta)=A+B \theta
$$

Within the overlap of the ascending and descending branch of the orbit, each SAR pixel is measured at two incidence angles. Thus, two co-registered complementary SAR images can be used to estimate the slope $B$ and linear incidenceangle normalization (Kaleschke and Kern, 2002).

Then, statistical, textural and spectral features are derived from ERS-2 SAR images using a sliding calculation window. Fast computational methods have been used for the calculation of the grey-level co-occurrence matrix (GLCM) which contains the conditional joint probabilities of all pairwise combinations of grey levels (Clausi and Zhao, 2002). The normalized extension difference (NED) derived from the spectral moments can be used to distinguish between the ice-free and sea-ice-covered ocean (Schmidt and Heygster, 1997). The above procedure requires the presence of swell in the image. However, ice concentrations derived from $85 \mathrm{GHz}$ SSM/I data corresponding to the SAR pixels are independent of the sea state. The gridding and interpolation of the ASI sea-ice concentration $C_{\mathrm{ASI}}$ data to the ERS SAR image grid was performed using continuous curvature splines in tension (Smith and Wessel, 1990). The features $f_{i}$ are scaled to the range $[0,1]$ by using the hyperbolic tangent function

$$
n_{i}=\frac{1}{2}\left[\tanh \left(\frac{f_{i}(x)-\mu_{f_{i}}}{\sigma_{f_{i}}}\right)+1\right]
$$

with mean $\mu_{f_{i}}$ and standard deviation $\sigma_{f_{i}}$ computed only once for all of the data used in order to preserve the classdependent biases. The resulting features $n_{i}$ reside in an $N$ dimensional unit-less space. For the results of this paper, we used only $N=2$ dimensions, the mean backscatter $\sigma^{\circ}$ and the ice concentration $C_{\mathrm{ASI}}$. More features calculated from the SAR image or from other sensors can be added easily using the same formalism.

Kohonen's Learning Vector Quantization (LVQ), a supervised neural network, was used for classification (Kohonen, 1997). LVQ approximates the Bayesian decision boundaries by a set of optimally placed reference vectors without a priori assumptions about the probability density functions.

The network is trained by learning from examples. Therefore representative examples of all occurring classes have to be selected. The classification result can be evaluated by using test data which were not used for the training.

\section{DATASET}

During ARTIST several satellite under-flights were carried out with the research aircraft Polar 2 and 4 of the Alfred Wegener Institute for Polar and Marine Research (AWI) while operating microwave radiometers, line scanners, radiation thermometer and a laser altimeter, as well as several sensors for measuring meteorological parameters.

The flight pattern of the Polar 4 aircraft on 12 March 1998 is shown in Figure 1 by the dashed white line. These data have been plotted over the ERS-2 SAR image and the ASI ice concentration as calculated from SSM/I data. The aircraft measurements and observations (600-1600 m flight level) were co-located to the ERS-2 SAR image pixels using aircraft position data (global positioning system (GPS), tilt, heading) and assuming uniform ice motion. The minimum air temperature on 11 March 1998 was $-40^{\circ} \mathrm{C}$ according to the ARTIST buoy 9372 at $81.8^{\circ} \mathrm{N}, 10.9^{\circ} \mathrm{E}$. Such cold temperatures promoted the growth of frost flowers. Backscatter values as high as those from the wind-roughened 
ocean sea surface (at $80.2^{\circ} \mathrm{N}, 11^{\circ} \mathrm{E}$ ) caused by the frost flowers (at $80.7^{\circ} \mathrm{N}, 8^{\circ} \mathrm{E}$ ) can also be seen in Figure 1.

\section{RESULTS}

An average incidence-angle dependence of $B=-0.3 \pm$ $0.1 \mathrm{~dB} \mathrm{deg}^{-1}$ was estimated for sea ice in a compacted marginal ice zone (Kaleschke and Kern, 2002). The value $B=-0.3 \mathrm{~dB} \mathrm{deg}^{-1}$ was used for a linear incidence-angle normalization.

The SAR image was annotated along the flight track with the surveillance logs, making the visual interpretation of the SAR image much easier. About 50 homogeneous areas of five different surface types were manually selected in the SAR image. Open water (OW), first- (FY) and multi-year ice $(\mathrm{MY})$, newly formed ice (NI) and newly formed ice with frost flowers (FR) were discriminated. The latter newly formed ice types are described as dark/light nilas and grey ice in the surveillance logs.

The mean backscatter value $\sigma^{0}$ was calculated using a sliding calculation window of $31 \times 31$ pixel size. The sea-ice concentration was calculated using the ASI algorithm (Kaleschke and others, 2001). The selected areas were used for training and testing of the neural network, respectively. The number of reference vectors for the LVQ algorithm was 500 .

The overall classification accuracy of the training and the independent test data was $95.7 \%$ and $81.5 \%$, respectively. The confusion matrix is given in Table 1. A total of 2717 randomly selected OW test data were classified correctly as OW (2662) and incorrectly as NI (51) and FY (34). The resulting classification error for $\mathrm{OW}$ is about $3 \%$. The classification errors of $\mathrm{NI}$ and FY are about 20-30\%. The worst result was achieved for FR which was confused with MY (about 50-100\% error). However, there would have been larger errors without the use of ice concentration data. Without such data there would also have been confusion between FR and OW. This example shows that the combined analysis of SSM/I and SAR data can considerably improve the classification accuracy.

The normalized radar cross-section $\sigma^{\mathrm{o}}$ of the newly formed ice covered with frost flowers was about -7 to $-2 \mathrm{~dB}$. The frost-flower-covered area was about $15 \times 15 \mathrm{~km}^{2}$, with a mean backscatter of $-5 \mathrm{~dB}$.

\section{CONCLUSION}

The backscatter value of newly formed ice can be as high as that of wind-roughened open water due to the influence of frost flowers. It is possible to separate the frost-flower and open-water signatures by the simultaneous analysis of SSM/I and SAR data. However, large errors remain due to the confusion of frost flowers with other ice types. To resolve these errors, other features must be considered for an advanced classification. Such features will be evaluated in an ongoing project.

\section{ACKNOWLEDGEMENTS}

The authors would like to thank the two reviewers for making useful suggestions. This research was funded by the German Research Foundation (DFG) under contract HE1746/5-2 and HE-1746/11-1. The ARTIST project was
Table 1. Confusion matrix of 10000 test data

\begin{tabular}{rrrrrr}
\hline & OW & NI & FY & MY & FR \\
\hline OW & 2632 & 51 & 34 & 0 & 0 \\
NI & 72 & 2443 & 428 & 158 & 31 \\
FY & 0 & 54 & 1475 & 457 & 28 \\
MY & 0 & 0 & 9 & 1067 & 531 \\
FR & 2 & 0 & 0 & 0 & 528 \\
\hline
\end{tabular}

funded by the Commission of the European Community under contract Nr. ENV4-CT97-0497-0487 (DG12-ESCY).

\section{REFERENCES}

Augstein, E. 2000. Final report on the Arctic Radiation and Turbulence Interaction Study (ARTIST). Contract Nr. ENV4CT97-0497-0487 (DG12-ESCY). Bremerhaven, Alfred-WegenerInstitut für Polar- und Meeresforschung.

Clausi, D. A. and Y. Zhao. 2002. Rapid extraction of image texture by co-occurrence using a hybrid data structure. Computers Geosci., 28(6), 763-774.

Comiso, J. C., D. J. Cavalieri, C. L. Parkinson and P. Gloersen. 1997. Passive microwave algorithms for sea ice concentration: a comparison of two techniques. Remote Sensing Environ., 60(3), 357-384.

Drinkwater, M. R. and G. B. Crocker. 1988. Modelling changes in the dielectric and scattering properties of young snow-covered sea ice at $\mathrm{GHz}$ frequencies. J. Glaciol., 34(118), 274-282.

Ebinghaus, R. and 7 others. 2002. Antarctic springtime depletion of atmospheric mercury. Environ. Sci. Technol., 36(6), 1238-1244.

Ezraty, R. and A. Cavaine. 1999. Construction and evaluation of 12.5-km grid NSCAT backscatter maps over Arctic sea ice. IEEE Trans. Geosci. Remote Sensing, GE-37(3), 1685-1697.

Hönninger, G. and U. Platt. 2002. Observations of $\mathrm{BrO}$ and its vertical distribution during surface ozone depletion at Alert. Atmos. Environ., 36(15-16), 2481-2489.

Kaleschke, L. and S. Kern. 2002. ERS-2 SAR image analysis for sea ice classification in the marginal ice zone. In IGARSS 2002, 22nd International Geoscience and Remote Sensing Symposium, 24-28 June 2002, Toronto, Canada. Proceedings. Piscataway, NJ, Institute of Electrical and Electronics Engineers, 3038-3040.

Kaleschke, L. and 6 others. 2001. SSM/I sea ice remote sensing for mesoscale ocean-atmosphere interaction analysis. Can. J. Remote Sensing, 27(5), 526-537.

Kohonen, T. 1997. Self-organizing maps. Second edition. Berlin, Springer Verlag. (Springer Series in Information Sciences.)

Martin, S., Y. Yu and R. Drucker. 1996. The temperature dependence of frost flower growth on laboratory sea ice and the effect of the flowers on infrared observations of the surface. J. Geophys. Res., 101(C5), 12,111-12,125.

McElroy, C. T., C.A. McLinden and J.C. McConnell. 1999. Evidence for bromide monoxide in the free troposphere during the Arctic polar sunrise. Nature, 397(6717), 338-341.

Perovich, D. K. and J. A. Richter-Menge. 1994. Surface characteristics of lead ice. J. Geophys. Res., 99(C8), 16,341-16,350.

Petit, J.-R. and 18 others. 1999. Climate and atmospheric history of the past 420,000 years from the Vostok ice core, Antarctica. Nature, 399(6735), 429-436.

Rankin, A.M., E.W. Wolff and S. Martin. 2002. Frost flowers: implications for tropospheric chemistry and ice core interpretation. J. Geophys. Res., 107(D23), 4683. (10.1029/ 2002JD002492.)

Richter, A., F. Wittrock and J. P. Burrows. 1997. GOME observations of tropospheric BrO. Geophys. Res. Lett., 25(4), 2683-2686. 
Schmidt, R. and G. Heygster. 1997. Use of ocean wave imaging to detect the marginal ice zone in ERS-SAR images. In Third ERS Scientific Symposium, 17-21 March 1997, Florence, Italy. Proceedings. Vol. 2. Frascati, European Space Agency, 959-962. (ESA Publication SP-414.)

Smith, W. and P. Wessel. 1990. Gridding with continuous curvature splines in tension. Geophysics, 55(3), 293-305.

Steffen, K. and J. Heinrichs. 1994. Feasibility of sea ice typing with synthetic aperture radar (SAR): merging of Landsat thematic mapper and ERS-1 SAR satellite imagery. J. Geophys. Res., 99(C11), 22,413-22,424.

Svendsen, E., C. Mätzler and T.C. Grenfell. 1987. A model for retrieving total sea ice concentration from a spaceborne dualpolarized passive microwave instrument operating near $90 \mathrm{GHz}$. Int. J. Remote Sensing, 8(10), 1479-1487.

Ulander, L.M. H., A. Carlström and J. Askne. 1995. Effect of frost flowers, rough saline snow and slush on the ERS-1 SAR backscatter of thin Arctic sea ice. Int. J. Remote Sensing, 16(17), 3287-3305.

Wagner, T. and U. Platt. 1998. Satellite mapping of enhanced $\mathrm{BrO}$ concentrations in the troposphere. Nature, 395(6701), 486-490.

Zabel, I. H. H., K.C. Jezek, S.P. Gogineni and P. Kanagaratnam. 1996. Search for proxy indicators of young sea ice thickness. J. Geophys. Res., 101(C3), 6697-6709. 